\title{
The Relationship between Knowledge of HIV/AIDS and Stigma towards HIV/AIDS Children among Caregivers at Shelter Home
}

Ezarina Zakaria, Wan Nornazmiera Wan Hamat, Nur Saadah Mohamad Aun

To Link this Article: http://dx.doi.org/10.6007/IJARBSS/v11-i6/9862

DOI:10.6007/IJARBSS/v11-i6/9862

Received: 08 April 2021, Revised: 10 May 2021, Accepted: 29 May 2021

Published Online: 15 June 2021

In-Text Citation: (Zakaria et al., 2021)

To Cite this Article: Zakaria, E., Hamat, W. N. W., \& Aun, N. S. M. (2021). The Relationship between Knowledge of HIV/AIDS and Stigma towards HIV/AIDS Children among Caregivers at Shelter Home. International Journal of Academic Research in Business and Social Sciences, 11(6), 425-431.

Copyright: (c) 2021 The Author(s)

Published by Human Resource Management Academic Research Society (www.hrmars.com)

This article is published under the Creative Commons Attribution (CC BY 4.0) license. Anyone may reproduce, distribute, translate and create derivative works of this article (for both commercial and non-commercial purposes), subject to full attribution to the original publication and authors. The full terms of this license may be seen at: http://creativecommons.org/licences/by/4.0/legalcode

Vol. 11, No. 6, 2021, Pg. 425 - 431

Full Terms \& Conditions of access and use can be found at http://hrmars.com/index.php/pages/detail/publication-ethics 


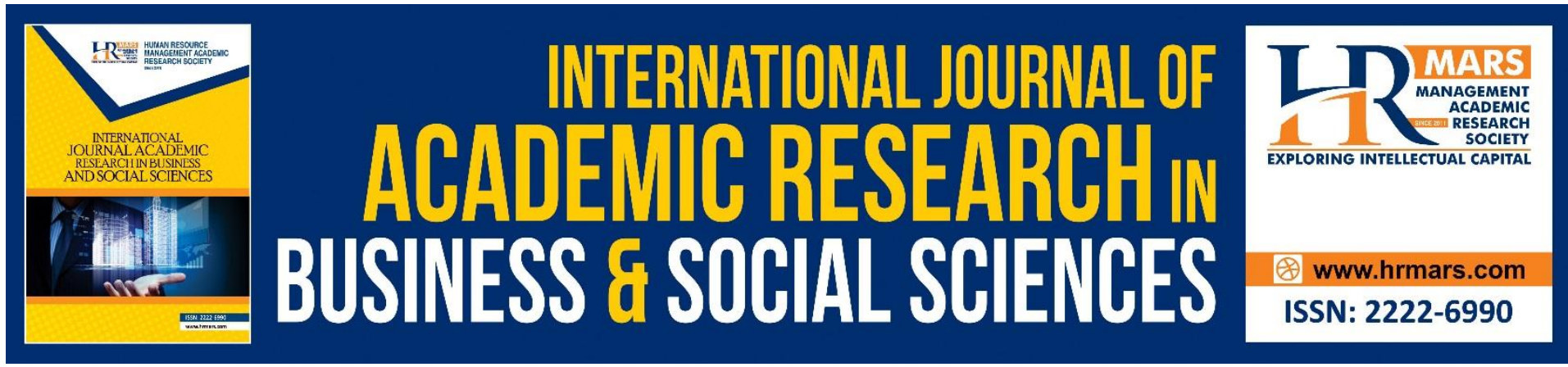

\title{
The Relationship between Knowledge of HIV/AIDS and Stigma towards HIV/AIDS Children among Caregivers at Shelter Home
}

\section{Ezarina Zakaria, Wan Nornazmiera Wan Hamat, Nur Saadah Mohamad Aun}

School of Psychology and Human Wellbeing, Faculty of Social Science and Humanities, Universiti Kebangsaan Malaysia, 43600 Bangi, Selangor, Malaysia

Email: ezaz@ukm.edu.my

\begin{abstract}
The increasing cases of HIV/AIDS have led to an increase in the number of children whose parents have died of HIV/AIDS. They are the AIDS Orphan, and their developmental needs are taken care of by either their next of kin or formal institutional caregiver after both parent's death. The inaccurate information about HIV/AIDS leads to these children being stigmatized. Previous studies have less focus on the formal institutional caregiver, particularly their acceptance of the AIDS Orphan. This study was conducted to measure the relationship between the caregivers' knowledge of HIV/AIDS and the stigma towards HIV/AIDS children who live in shelter homes. This study applied a quantitative data analysis method and carried out a survey design cross-sectionally in seven shelter homes. A total of 140 caregivers were purposively selected to participate in the study. Data were collected using a questionnaire taken from the HIV Knowledge Questionnaire (HIV-KQ-18), Measuring The Degree of HIVrelated Stigma and Discrimination in Health Facilities and Providers, and the Manual of Measuring HIV Stigma and Discrimination among Health Facility Staff Questionnaire. The results indicated that $83.6 \%$ of respondents have moderate knowledge about HIV/AIDS, and $80.7 \%$ of respondents had a moderate level of stigma towards HIV children.. Findings suggesta significant correlation between knowledge of HIV/AIDS and stigma $(r=.269, k<001)$. The lack of knowledge about HIV transmission leads to stigma among caregivers.

The results of this study emphasize the importance of having a precise knowledge of the HIV/AIDS medium of transmission, prevention, and treatment in order for the caregivers to manage the AIDS Orphan without discrimination. The study also highlights the implications for recognizing measures to reduce stigma among caregivers as it reflects the quality of health and psychosocial development of HIV/AIDS children under their care.
\end{abstract}

Keywords: Knowledge of HIV/AIDS, Stigma, HIV/AIDS, Children, Caregiver

\section{Introduction}

Human Immunodeficiency Virus, better known as HIV, could slowly destroy the human immune system. While AIDS is an abbreviation for 'Immune Deficiency Syndrome' which is 
caused by the HIV retrovirus and is the last stage of HIV infection. Individuals who are infected with HIV are at risk of contracting other diseases due to the body's inability to fight the disease. In the final stages of infection, People Living With HIV (PLHIV) will experience opportunistic infections such as shingles, candidiasis, pneumonia, skin cancer and are usually the cause of death (MAC 2018). Malaysia Ministry of Health (2017), reported the main cause of HIV transmission until 2016 was promiscuous sex activities among society. Since the emergence of the HIV/AIDS pandemic in Malaysia around 1986 until now, the number of HIV infections and deaths due to AIDS has continued to increase from the year onwards. Table 1 shows the statistic of HIV/AIDS cases from 1986 until December 2016. Statistics show HIV infection reported cases is 111,916 , while reported cases for AIDS infection is 23,717. Based on the analysis of the cases done by the Malaysian AIDS Council, a total of 1,146 cases of children under 13 years were infected with HIV/AIDS until December 2016 (Malaysian AIDS Council 2016).

Table 1: Total reported HIV/AIDS cases and death in Malaysia (1986 - December 2016)

\begin{tabular}{llll}
\hline Year & HIV Infection & AIDS Cases & AIDS Death \\
\hline 1986 & 3 & 1 & 1 \\
2006 & 76389 & 12505 & 9155 \\
2016 & 111,916 & 23717 & 18827 \\
\hline
\end{tabular}

Sources:Malaysian AIDS Council, 2016.

HIV/AIDS causes an increase in the number of children affected, especially when the death of parents due to HIV/AIDS and the children status itself is also HIV seropositive. At one point, a significant effect increase in the number of children orphaned by AIDS every year. The worrying about psychosocial impact of HIV/AIDS for PLHIV still ongoing despite, many awareness and prevention programs implemented by governments and non-government agencies (UNAIDS, 2016; Malaysia AIDS Council, 2016). The scenario happen due to individuals attitude who only interested to understand and obtain information related to HIV/ AIDS after themselves or any of their family members are infected and diagnosed with seropositive HIV. Individuals who are normally infected and involved actively with HIV issues belong to the productive age group with family and children. Hence, when seropositive parents die because of HIV/AIDS, child care is also affected. The extended family such as grandparents or other relatives faced difficulties to take over the informal subsitution child care. So the placement and caregiving of these children will be taking over by a formal shelter home, include children with or without HIV. The formal or informal responses to the HIV/AIDS psychosocial impact related to stigma and negative perception remain existent including caregivers in institutions. Although most of these caregivers are social workers and healthcare workers, there is still a lack of studies focused on them who work in institutions. Therefore, this article will discuss the studies finding related to knowledge and stigma on seropositive HIV children among caregivers in shelter home institutions.

\section{Knowledge and Stigma on HIV/AIDS}

The roles of knowledge of HIV/AIDS determine undeniable stigma level and gaining attention from certain researchers. Knowledge is defined as the comprehensive understanding of certain issues as a whole and able to change a person's attitude and behavior (Okumu, 2017). Rachel et al (2015), their study showed knowledge is an important measurement tool to modify the stigma level among caregivers who worked in shelter home institutions including 
social workers. Less knowledgeable social workers about HIV/AIDS transmission and prevention are seen to display their personal stigma and potentially cause problems in handling cases (Okeoma et al., 2016). Apart from that, West et al (2016) also emphasized that knowledge is an important key to prevent HIV/AIDS. He added HIV transmission can be prevented by increasing accurate pieces of knowledge based on reliable sources. Knowledgeable caregivers of HIV/AIDS children display less labeling and discrimination against HIV/AIDS children in institutions (Rahmayani, 2013). Norfazilah et al (2018), also manifest the knowledge on HIV/AIDS transmission, prevention and treatment have a significant relationship with stigma.

Next, stigma can describe a situation that contains elements of labeling, prejudice, stereotyping, and discrimination against stigmatized individuals (Ranjan et al. 2015). Normally, stigma occurs due to individual personal fear of the disease and infection by HIV, as well as associated HIV/AIDS with other negative activities (Kuete, 2016). Past studies have stated, the lack of accurate knowledge regarding HIV/AIDS transmission leads to the feeling of fear to have direct contact with PLHIV among community members and their caregivers, further affecting seropositive HIV children in institutions (Richelle \& Victoria, 2017). The findings are supported by the study carried by Sohn (2012), who showed the knowledge about HIV/AIDS is a major arousing factor of negative perception towards PLHIV and the disease itself among society. Mislead information and false knowledge about HIV infection may drive fear and stigma among HIV-positive children caregivers in institutions.

There are three elements of the stigma against HIV/AIDS children, such as fear of direct contact, disclosure of identity as a caregiver of HIV children, and views on HIV (Ezarina, Saadah \& Nornazmiera, 2018). Fear of direct contact occurs when caregivers make a negative interpretation of the way HIV/AIDS is transmitted and indirectly encourages them to avoid direct contact such as touching, sharing food containers, and others. While the disclosure of the identity as guardians of children with HIV/ AIDS kept confidential by a guard because they worry it might affect their social interaction with society. The majority of society including caregivers often associate PLHIV with deviant behavior and God's retribution for their sins (Mao et al., 2019; Nyblade et al., 2013; Beardsley et al., 2010). Most people easily feel that PLHIV deserves to be stigmatized for adopting deviant lifestyles. It is no exception to the cases of children who are infected and inherited the virus from their mothers through pregnancy. The situation illustrated the possibility of superficial knowledge related to HIV/AIDS transmission thus causing caregivers to also stigmatize HIV-positive children in institutions. Persistent stigma has a devastating impact on HIV/AIDS children. In addition to facing an endless burden of illness, HIV-positive children also suffer from emotional disorders and lack of self-confidence to socialize. A study by Jacobi et al (2013), reported a total of 60 percent of respondents were stigmatized and 30 percent of them had been verbally abused and physically impaired. Other than that, the results of the study also found 50 percent of respondents felt ashamed and guilty, while 40 percent of them blamed themselves due to their HIV/AIDS status. This secondary stigma can happen to children and the psychosocial impact of HIV/AIDS will left a negative effect if it left unaddressed.

Past studies have proven that most healthcare staff, counselors, and social workers still lack of knowledge and have personal attitudes at low and negative levels. The lack of understanding about HIV transmission is seen as a driven factor increasing numbers of HIV 
prevalence and mortality (Sarasuphadi, 2018). A study by Kwena et al (2013), found that 1893 respondents who are healthcare staff gave stigma and showed negative attitudes towards HIV patients. Plus, the lack of proper knowledge on HIV causes AIDS patients to have difficulty accessing antiretroviral therapy and received unstandardized treatments from the healthcare staff. Apart from receiving poor treatment, they also showing procrastined behavior while providing treatment for PLHIV thus causing the patient to feel angry and humiliated by the healthcare providers. These negative manifested attitudes and stigmatization cause PLHIV to decide not to continue their treatments (Masoudnia, 2015; Eaton et al., 2015). Thus, stigma is expected to be a major obstacle for caregivers including social workers in providing assistance services to HIV/AIDS patients effectively.

Besides, stigma causes PLHIV to faced social rejection and considered not to play roles as members of society because of their past involvement in high-risk activities that deviates from the religious path (Friendland, 2018). Li et al (2017), stated that stigma is divided into three dimensions namely control, the danger of disease effects, and societal views. The control dimension explained stigmatization among caregivers is based on belief and moral held about the transmission of HIV/AIDS-associated with promiscuous sex, so HIV infection through negative activities is considered a commensurate response to their negative behavior. Whereas on the dimension of danger disease effects, the caregivers leave for fear of stigma if infected. Fear is described by caregivers because the pandemic is contagious and there are no specific medications or treatments can cure the disease. While in society view dimension, PLHIV experienced negative feedback and responses such as boycott, denial of rights, social denial from the society that affects their social interaction with the surrounding. Failure to curb stigma among formal caregivers will not only result in neglected care of HIV children but also risk deteriorating health, stunted development, mental and emotional deterioration.

HIV/AIDS children become vulnerable in various dimensions (Sarah et al., 2018). They not only face challenges and difficulties in managing serious health problems from time to time due to infections or opportunistic symptoms but also have to deal with issues of stigma and discrimination (Zamir, Lorber \& Hermon, 2014). These children are merely victims and can not be a benchmark for being stigmatized by society and caregivers. The stigma caused the emergence of shame, not accepted, rejection, isolation and lead to other negative attitudes (Freindland et al., 2018). Other than that, stigma also has a negative impact on HIV-positive children because their right to education is denied, and even more, pitiful children with HIV do not have the opportunity to live a normal life like other children (George et al., 2012). This situation clearly showed the stigma has a great impact on children's development. Children with HIV/AIDS do not necessarily live with their biological family or relatives. Many of those living in institutions, especially children who have been the death of parents due to HIV / AIDS. Nalasamy and Hajar (2013), found that children who lived in institutions were less successful in achieving their best self-potential because of discrimination, received less stimulation as well as caregiver attention. If the child's environment at the institution is under the influence of stigma and discrimination, the child might not have the opportunity to experience a healthy developmental process like others (Goldberg \& Short, 2016).

The children's lives in institutions face many challenges. Besides having big changes in life at the institution such as being part of new family circles and school (Nalasamy \& Siti Hajar 
2013), the seropositive HIV children also have to deal with daily routine treatment as well as different medications intake and require direct commitment from caregivers (Das et al., 2017). The challenge arises in order to form good social interaction and relations, especially for the caregiver who lacks knowledge about HIV/AIDS (Ofori-Atta, 2018; Okeoma et al., 2016). If a caregiver's views and knowledge about HIV/AIDS are negative, they are actually putting themselves under the influence of stigma (McHenry et al., 2017; Messer et al., 2010). The situation leads to arising questions about careers level of knowledge in HIV/AIDS and stigma among caregivers of children with HIV/AIDS in institutions. This issue makes a study that focuses on the knowledge and stigma on HIV/AIDS among caregivers in child protection institutions become very significant. In addition, most of the previous studies have focused more on healthcare staff and HIV/AIDS knowledge as well as the stigma of HIV/AIDS children in hospitals (Eaton et al. 2015; Kwena et al. 2013; Ekstrand et al. 2013; Sekoni dan Owoaje 2013; Rajwani 2012). Less research conducted focusing on caregiving involved in social care such as in child shelters.

Based on the highlighted issues, a study was conducted to :

I. Identify the level of knowledge and stigma about HIV/AIDS among child caregivers in institutions.

II. Measure the relationship between HIV/AIDS knowledge and stigma against HIV/AIDS among child caregivers in institutions.

\section{Methodology}

The design of this study was conducted cross-sectional by using quantitative data analysis methods. The survey study method was conducted in seven selected HIV/AIDS children shelter homes. The targeted population is the caregivers who directly work at the institutions. Whereas the sample consisted of selected social workers and the shelter homes managers using the purposive sampling technique. The questionnaire consists of three main sections namely i) Section A-demographic information of respondents, ii) Section B-knowledge of HIV/AIDS, and iii) Section C-stigma of HIV/AIDS. The collection of data on a total of 140 respondents were successfully carried out using a questionnaire. The research instruments used are as follows:

i) The HIV Scale is a combination of the HIV Knowledge Questionnaire (HIV-KQ-18) by Carey and

Schroder (2001) and the HIV Scale taken from Measuring The Degree of HIV-related Stigma and Discrimination in Health Facilities and Providers (Beardsley et al. 2010). The HIV-KQ-18 test tool and the HIV Scale were combined into a new questionnaire. The HIV scale contains 23 questions and is divided into two subscales, namely knowledge about how the HIV virus is transmitted (13 items) and knowledge about HIV prevention and treatment (10 items).

ii) The Stigma Scale is a measurement tool developed by Nyblade et al., (2013); Beardsley et al. (2010). The Stigma scale was taken from the Manual Measuring HIV Stigma and Discrimination among Health Facility Staff Questionnaire (Nyblade et al. 2013) and Measuring the Degree of HIV-related Stigma and Discrimination in Health Facilities and Providers (Beardsley et al. 2010) to measure the level of stigma among caregivers of HIV children in shelter institutions. The Stigma scale contains 35 questions and is divided into three subscales namely fear of direct contact (12 items), 
disclosure of identity as a caregiver of HIV children (10 items) and views on HIV (13 items).

A Likert scale of 1-5 which is "strongly disagree, disagree, unsure, agree and strongly agree" was used as a scoring method in the study. The reliability value is $<0.72$. Detailed data is tabulated in Table 2 below. Data were analyzed using Statistical Package for the Social Science for Windows (SPSS) software. The analysis is divided into two based on objectives, namely descriptive analysis, and correlation analysis.

Table 2 : Analysis Reliability Test Tool.

\begin{tabular}{lll}
\hline Tools & Alpha Cronbach & Item \\
\hline HIV/AIDS level of knowledge & 0.720 & 23 \\
Stigma on HIV/AIDS & 0.938 & 35 \\
\hline
\end{tabular}

\section{Results}

The demographic analysis results include the background of 140 respondents who work in seven shelter homes. Information regarding respondents' names, location of the institution is not reported in this article for the purpose of data confidentiality. The demographic respondents' description is stated in Table 3 . The analysis shows, the highest respondents age distribution of the study is the range between $30-39$ years (42\%), the second-highest is the age of $19-29$ years (35\%) followed by $14 \%$ age between $40-49$ years and the lowest is $9 \%$ of respondents aged between 50-59 years. Meanwhile, for the distribution by gender, most of the caregivers are women, which is represented by 107 female respondents (76\%), followed by men were 12 respondents (33\%). In terms of educational background, most respondents are graduated from high school which is 80 individuals (58\%), the second-highest which is 37 respondents(26\%) who is obtained a degree and the rest 20 respondents (14\%) obtained a diploma.

As for the position's classification and grades, a total of 116 individuals (83\%) are social workers followed by a total of 24 individuals (17\%) who are managers at the institutions. The majority of the staff served in institutions between 2-10 years, which is 73 respondents (52.1\%) and 30 respondents were served more than 10 years.

According to the caregivers' frequency in receiving training on HIV/AIDS distribution, a total surveyed of 106 caregivers (76\%) in institutions stated they had never received training, while the total frequency number of caregivers attend training twice a year in 22 respondents ( $15 \%)$, followed by 12 respondents (9\%) who joined training once a year. As for the experience of respondents who attended any training, a total of 106 respondents (76\%) said they had never attended training related to the children with HIV/AIDS management courses while only 34 respondents (24\%) attended training related to the management of children with HIV/AIDS. The finding also reported that a total of 7 respondents (5\%) had attended the HIV Child Management Training, 5 of them (3.6\%) attended the HIV Management Course, 5 respondents (3.6\%) underwent HIV Care and Infection training. Besides, a total of 3 respondents (2.1\%) attended the Child Care Counseling training, 3 of them $(2.1 \%)$ attended the training from the Malaysian AIDS Council, 3 other respondents (2.1\%) attended the training from the HIV/AIDS Seminar, followed by 3 people $(2.1 \%)$ attended Shelter Home Operating training. Next, a total of 2 respondents (1.4\%) attended 
training at the Minimum Standards in Children Care Center by MAC \& UNICEF, 2 respondents (1.4\%) attended training related to Supporting, Counseling, Medication and etc and 1 respondent $(0.7 \%)$ attended the People Management infected with HIV/AIDS. Detailed data concerning the training received is shown in table 3.

Table 3: Demography Profile

\begin{tabular}{|c|c|c|}
\hline Respondent Profile & Frequency & Percentage (\%) \\
\hline \multicolumn{3}{|l|}{ Age } \\
\hline $19-29$ & 49 & 35 \\
\hline $30-39$ & 59 & 42 \\
\hline $40-49$ & 20 & 14 \\
\hline $50-59$ & 12 & 9 \\
\hline \multicolumn{3}{|l|}{ Sex } \\
\hline Male & 33 & 24 \\
\hline Female & 107 & 76 \\
\hline \multicolumn{3}{|l|}{ Ethnic Group } \\
\hline Malay & 132 & 94 \\
\hline Chinesse & 5 & 4 \\
\hline India & 3 & 2 \\
\hline \multicolumn{3}{|l|}{ Religoius } \\
\hline Islam & 130 & 92.9 \\
\hline Christian & 5 & 3.6 \\
\hline Buddha & 4 & 2.9 \\
\hline Hindu & 1 & 0.7 \\
\hline \multicolumn{3}{|l|}{ Maritial Status } \\
\hline Single & 58 & 42 \\
\hline Married & 80 & 57 \\
\hline Divorcee & 2 & 1 \\
\hline \multicolumn{3}{|l|}{ Education Level } \\
\hline High School Graduate & 80 & 58 \\
\hline Diploma & 20 & 14 \\
\hline Degree & 37 & 26 \\
\hline Others & 3 & 2 \\
\hline \multicolumn{3}{|c|}{ Post Classification and Grade Distribution } \\
\hline Manager & 24 & 17 \\
\hline Social Worker & 116 & 83 \\
\hline \multicolumn{3}{|l|}{ Working Period Distribution } \\
\hline 2 years below & 37 & 26.4 \\
\hline $2-10$ years & 73 & 52.1 \\
\hline 10 years and above & 30 & 21.4 \\
\hline
\end{tabular}


INTERNATIONAL JOURNAL OF ACADEMIC RESEARCH IN BUSINESS AND SOCIAL SCIENCES Vol. 11, No. 6, 2021, E-ISSN: 2222-6990 @ 2021 HRMARS

Income

RM1000-RM3000

RM3100-RM5000

RM5000 and above
126

13

1
90

9

1

Frequency of Receiving Training Distribution

Never attend

106

1 time per year

2 times per year

Training Distribution

Yes

No

Types of Training Distribution

Child Care Counseling 3

Malaysia AIDS Council

Minimum standards in Children Care Centre by 2

MAC \& UNICEF

Shelter Home Management

Supporting Counseling, Medication and etc

HIV/AIDS Infected and Management Course

Management of HIV Children 


\section{Objective 1 : Identify Level of Knowledge of HIV/AIDS and Stigma on Children with HIV/AIDS} Caregiver knowledge level of HIV/AIDS

Operationally, bits of knowledge of this study refers to caregiver's understanding of basic transmission, prevention, and treatment of HIV/AIDS in sheltered institutions. Based on the analysis, caregivers are knowledgeable about HIV transmission according to the highest mean showed that is 41.685 (s.p. 6.708). As for the knowledge of prevention and treatment, the mean reading is 27.871 (s.p. 5.615). Table 5 showed the mean results and standard deviation for HIV/AIDS knowledge scale.

Table 5: Mean and standard deviation results of level of knowledge in HIV/AIDS

\begin{tabular}{llccc}
\hline Scale & Min score & Max score & Mean & $\begin{array}{l}\text { Standard } \\
\text { Deviation }\end{array}$ \\
\hline Knowledge on HIV transmitted & 24 & 57 & 41.683 & 6.708 \\
$\begin{array}{l}\text { Knowledge on HIV prevention } \\
\text { and treatment }\end{array}$ & 12 & 39 & 27.871 & 5.615 \\
\hline
\end{tabular}

As for the results on the HIV/AIDS analysis level of knowledge, the majority of the caregivers have a moderate understanding of HIV/AIDS which is 117 respondents (83.6\%). While a total of 14 respondents (10\%) have higher knowledge related to HIV/AIDS, followed by 9 respondents (6.4\%) with a low level of knowledge. As reported in table 6, show the finding of the distribution of HIV/AIDS knowledge levels.

Table 6 : Distributiom of HIV/AIDS level of knowledge

\begin{tabular}{lll}
\hline Level of knowledge & Frequency & Percentage (\%) \\
\hline High & 14 & 10 \\
Medium & 117 & 83.6 \\
Low & 9 & 6.4 \\
\hline Total & 140 & 100 \\
\hline
\end{tabular}

Note: Low (25 - 53), Medium (54 - 84), High (85 - 115)

Caregiver Level of Stigma toward HIV/AIDS

Operationally, stigma refers to conditions such as rejection, prejudice, and boycott among HIV/AIDS children caregivers in sheltered institutions. The focus in this section is to study the affected child care and treatment caused by stigma among caregiver institutions towards seropositive HIV Children. The results found that the stigma subscale view items on HIV/AIDS among caregivers in shelter homes was highest with a mean of 40.114 (s.p 8.005), followed by fear in direct contact which is a mean of 34,542 (s.p 6.312). While the lowest mean for the stigma subscale belongs to the disclosure of identity as a caregiver of HIV/AIDS children which is 19.014 (s.p 6.914). Table 7 shows the mean and standard deviation results for the HIV/AIDS Stigma Scale. 
INTERNATIONAL JOURNAL OF ACADEMIC RESEARCH IN BUSINESS AND SOCIAL SCIENCES Vol. 11, No. 6, 2021, E-ISSN: 2222-6990 @ 2021 HRMARS

Table 7 : Mean and standard deviation result on HIV/AIDS stigma scale

\begin{tabular}{lllll}
\hline Stigma Scale & $\begin{array}{l}\text { Minimum } \\
\text { Score }\end{array}$ & $\begin{array}{l}\text { Maximum } \\
\text { Score }\end{array}$ & Mean & $\begin{array}{l}\text { Standard } \\
\text { Deviation }\end{array}$ \\
\hline Perspectives on HIV/AIDS & 19 & 63 & 40.114 & 8.005 \\
$\begin{array}{l}\text { Feels scared to have direct } \\
\text { contact with HIV patient }\end{array}$ & 18 & 56 & 33.820 & 6.312 \\
$\begin{array}{l}\text { Identity disclosure } \\
\text { HIV/AIDS caregiver }\end{array}$ & 10 & 46 & 19.014 & 6.914 \\
\hline
\end{tabular}


Meanwhile, the results for the level of stigma of caregivers towards HIV children showed the majority of caregivers had a moderate level of stigma against HIV-positive children, which was 113 respondents $(80.7 \%)$. Plus a total of 23 respondents (10.4\%) had a low level of stigma followed by 4 respondents(2.9\%) had a high level of stigma. Table 8 reports the findings of the distribution level of stigma among caregivers of children with HIV / AIDS in the institution.

Table 8: Distribution of HIV stigma level

\begin{tabular}{lll}
\hline Stigma Level & Frequency & Percentage (\%) \\
\hline High & 4 & 2.9 \\
Medium & 113 & 80.7 \\
Low & 23 & 10.4 \\
\hline Total & $\mathbf{1 4 0}$ & $\mathbf{1 0 0}$ \\
\hline
\end{tabular}

Note: Low (35 - 81), Medium (82 - 128), High (129 - 175)

Objective 2 : To measure the relationship between knowledge and stigma about HIV/AIDS

Knowledge refers to the understanding of something and able to influences a person's actions or practices. Nicole, Joshua \& Clifford (2019) and Richelle \& Foster (2017), emphasized the importance of a handful of knowledge about HIV/AIDS as the key to preventing HIV transmission. Lack of accurate knowledge on how HIV/AIDS is transmitted will lead to misunderstanding and creating feelings of fear among the community including caregivers in institutions. Previous research focusing on the psychosocial impact of HIV/AIDS has often documented the importance of efforts to curb HIV transmission by increasing accurate knowledge about HIV through reliable sources and in turn influencing the tendency to reduce stigma. In fact, they also highlighted the relationship between stigma and discrimination against HIV/AIDS with misinformation. Stigma also refers to the social groups that deviated and behave out of ideal norms and the idea was constructed against them (Brandon et al. 2019). Whereas according to (Andrew et al. 2018), stigma against PLHIV is a major obstacle to effective and sustainable prevention, care, treatment, and support. Hence, this This study has measured the relationship between two key variables on caregivers of HIV/AIDS children in institutions.

Inferential analysis was performed to describe the relationship between the study variables and to test the study hypotheses. The analysis used was correlation analysis and significance value of $k$ is less than $0.01(k<0.01)$ and $0.05(k>0.05)$. The correlation analysis results show, there is a significant relationship between knowledge of HIV/AIDS with stigma against HIV/AIDS children that is $r(140=.269, k<0.01)$. It mean, the knowledge about HIV/AIDS transmission, and treatment has direct relationship with caregivers stigma against children with HIV/AIDS children lived in shelter homes. Caregivers who are knowledgeable on HIV transmission, prevention and subsequent treatment will have a low stigma against HIV/AIDS children in sheltered institutions. Table 9 shows the details of the analysis results. 
Table 9: Pearson Correlation between Knowledge of HIV/AIDS and Stigma against HIV/AIDS Children

\begin{tabular}{lclc}
\hline Variation & N & R Value & Sig \\
\hline Knowledge about HIV/AIDS & 140 & $.269^{* *}$ & 0.01 \\
Stigma on children with HIV/AIDS & & &
\end{tabular}

**Significant level 0.01

Based on the analysis between the subscales, the subscale of knowledge about HIV/AIDS that is knowledge about HIV prevention and treatment has a significant relationship with the subscale of stigma against HIV/AIDS children that is fear of direct contact (significant value $r=.380, k<0.01$ ). The low level of knowledge leaves a negative impact on caregivers' daily life as they might avoiding from dealing with children with HIV/AIDS directly. They will be afraid to have direct physical contact as for their fear of being infected while managing HIV/AIDS children in institutions. It means the inaccurate knowledge of HIV/AIDS leads to difficulties for caregivers in managing children with HIV/AIDS physically and affected their social interaction with others at once. Table 10 shows the result details of the analysis.

Table 10: Relationship between Knowledge Subscale on HIV/AIDS (Prevention and Treatment) and Stigma Subscale towards children with HIV/AIDS (fear of direct contact)

\begin{tabular}{lccc}
\hline Relationship between subscale & $\mathbf{N}$ & r value & Sig \\
\hline $\begin{array}{l}\text { Knowledge on HIV prevention } \\
\text { and treatment }\end{array}$ & 140 & $.380^{* *}$ & \\
& & & 0.00 \\
Fear of direct contact & &
\end{tabular}

**Significant level 0.01

The finding of this study surely supported study findings from previous researches regarding the relationship of HIV/AIDS knowledge with the stigma surrounding HIV itself. Other studies documented similar findings as this research is the study conducted by Nicole, Joshua \& Clifford (2019); Mulatu et al. (2018); Hewko et al. (2018); Demiral (2018): Khadijeh and Sadigheh (2016) and Rajwani (2012). The right knowledge is important to ensure the seropositive children received stigma-free care and treatment, also help in preventing mistakes happen in institutions daily management. In addition, knowledge on HIV/AIDS transmission, and related to care and treatment also important in reducing the level of individuals' fear while working directly with PLHIV. Competence through knowledge as well as measures to protect themselves when handling infected with caregivers of children. By it right, this research has confirmed the existing relationship between knowledge and stigma. The result show, the deeper the knowledge the lower the level of stigma in caregiver towards PLHIV.

\section{Discussion}

The results presented the knowledge of HIV/AIDS among AIDS Orphan caregivers is still at a moderate level. Their lack of exposure through training on and programs related to HIV/AIDS transmission, prevention, and treatment are identified, all these would help them increase 
their personal level of knowledge. Other than that, the caregiver's full involvement in handling and managing care training programs also at a moderate level. The existing knowledge gaps among children with HIV/AIDS caregivers in shelter homes especially social workers can be tackled and addressed through regular training. Handful caregivers with comprehensive knowledge of HIV/AIDS are best described as calmer and confident while handling the needs of HIV/AIDS children. An institution with a knowledgeable and comprehensive caregiver able to deliver effective assistance for the child in the right amount without stigmatization. In fact, the competent caregiver will form positive interactions with the child itself. A stigma-free relationship leads to excellent self-acceptance, helps in identifying psychosocial impacts of HIV/AIDS, and able to formulate effective intervention plans at once.

This scenario requires specialization and concerted effort planned by the agency. The focus should be providing HIV/AIDS knowledge from all aspects such as healthcare, transmission, prevention, and treatment. Information on the transmission and prevention of HIV / AIDS is a key important factor in ensuring children with HIV become skilled and sensitive to pandemic transmission patterns. In addition, caregivers also need to get exposed to the children's psychosocial impact. Both knowledge on healthcare skills and identifying psychosocial impact need to move in tandem, so their competency in handling case management at the agency can be enhanced and improve. Automatically it will dispel the stigma due to inaccurate negative perception among staff in the institution. The current situation indicates the occurrence of an increase in the numbers of individuals infected with HIV/AIDS while the numbers in informal caregiving settings among families are lesser. This phenomen leads to increase formal institutional protection of children with HIV / AIDS in Malaysia. Thus, it requires every shelter home to have knowledgeable and stigma-free staff while working with seropositive children. Although the staff is qualified with various academic backgrounds, the need to have non-stigmatized and competent staff should be emphasized with specific knowledge especially the person who will handle children with HIV/AIDS. The appropriateness in fulfilling the competency requirement is important under The Convention on the Rights of the Child (CRC) seeks to ensure that all children regardless of status including seropositive children deserve access to the right protection and receive competent services. Hence, caregivers who are competent in managing children with HIV/AIDS have a better ability to formulate assistance strategies according to the needs of the child without discrimination.

The continuous stigmatization against HIV/AIDS children still occurs due to the lack of accurate knowledge and information related to HIV/AIDS. In fact, more myths are spread about HIV/AIDS than the actual facts. Discrimination situations are often documented by other researchers, including health care staff in institutions. Plus while their feeling and need are ignored, HIV -positive individuals experienced less friendly treatment than other patients. The exact situation happens in sheltered institutions with caregivers who are less willing to accept HIV/AIDS as clients and insensitive to HIV/AIDS-related issues. The study findings on childcare in sheltered homes also provide similar results, the analysis shows stigma still exists among caregivers even at a moderate level and under control. If these caregivers shortcomings issues still left unchecked, it will forever expose HIV/AIDS children to various problems. Undeniably there is a tendency that the caregivers of children with HIV also face stigmatization by society due to their duty as patients caretakers. The pressure and stigma might also become pushing factors to put the blame on the children under their care. 
Thus, when the stigma of HIV/AIDS occurs, social acceptance should be the main focus. Twisted the way of thinking to improve and rectify the situation, this tips not only imply by the PLHIV but also their caregivers especially in changing their self-acceptance towards the targeted group in their care. If the gap repeatedly occurs in a daily relationship, the case manager may not be able to cooperate well as expected. Plus, The Covering Technique Approach can be practiced in addressing the stigma among caregivers towards HIV/AIDS children. Throughout this method, the caregiver able to change their own perception by assuming society might be ignorant and uneducated so they can easily arbitrarily stigma on others.

Besides, the empathy values should be possessed by caregivers in themselves. The ability to understand the concurrent situations and child feelings is important. The open attitude between caregivers and children will enhance better interaction. After the loss of family members due to death and major support sources, the seropositive child in dire needs to be accepted and compassion from the caregivers as their substituted sources of strength to face the HIV/AIDS psychosocial challenges in a long period of time. It means, the caregivers who work with HIV/AIDS sheltered homes need to be sensible and accepted their role as children guidance, they need to protect the child from any form of abuse, violence, exploitation, and discrimination, plus able to provide quality and effective service under The Children Act 2001 and The Convention on the Rights of the Child.

Recognizing the potential impact on the quality of health and psychosocial development of HIV/AIDS children in institutions, measures to reduce stigma among caregivers should be implemented. The Malaysian AIDS Council has pointed out five main objectives of assistance to people living with HIV/AIDS, namely raising awareness, preventing the spread, eliminating discrimination and stigma against people living with HIV/AIDS, ensuring the quality of life for people living with HIV/AIDS. AIDS, providing care and support for individuals living with HIV/AIDS in Malaysia. The awareness and specific programs regulating knowledge related to HIV/AIDS are certainly necessary for carers. It automatically helps in improve and corrected the confusing facts, reduce stigma among caseworkers, social workers, and other management staff who work closely with PLHIV at the institutions. Positive changes can be identified among program participants especially when there is an increase in individual's morale and self-motivation, the decrease in misperception and stigma, and reduction in stress level. Therefore, the awareness program approach needs to be extended to caregivers of HIV/AIDS children in shelter homes as a concerted effort to improve the quality of care and management, protect children's rights, improve access to services and expand research on effective treatment and prevention.

\section{Conclusion}

Results indicated that $83.6 \%$ of respondents have moderate knowledge about HIV/AIDS, and $80.7 \%$ of respondents had a moderate level of stigma towards HIV children. Findings suggest a significant correlation between knowledge of HIV/AIDS and stigma ( $r=$ $.269, \mathrm{k}<001$ ). The lack of knowledge about HIV transmission among caregivers mould their acceptance towards AIDS Orphan. Thus, adds to these children being stigmatized.

Formal caregivers incompetence determine the developmental risk of children with special needs due to HIV/AIDS. A competent caregiver will reflect a none judgemental case management services due to their high level of HIV/AIDS knowledge. Thus, it is crucial to 
initiate proper professional casework training to manage the AIDS Orphan without discrimination. Consequently, efforts to protect HIV/AIDS children in ensuring optimal child development are based not only on providing services alone. The focus should be providing insights from all aspects such as healthcare, HIV/AIDS transmission, prevention, and treatment. Information on the transmission and prevention of HIV / AIDS is a key important factor in ensuring caregivers become skilled and sensitive to pandemic transmission patterns. This scenario requires specialization and concerted effort planned by the agency. In addition, caregivers also need to get exposed to the children's psychosocial impact. Both knowledge on healthcare skills and identifying psychosocial impact need to move in tandem, so their competency in handling case management at the agency can be enhanced and improve. Every child deserves the right to live a similar life, including HIV-seropositive children, despite being in an institution after the death of a parent due to HIV/AIDS. Therefore, under the references of the Convention on the Rights of the Child (CRC) and any particular Children Act applied worldwide, a competent caregiver involvement is essential in ensuring effective HIV/AIDS case management services provided for the children. Holistic participation of all formal institutional caregivers also creates a positive opportunity for the children to grow up physically, mentally and emotionally free of discrimination.

\section{Acknowledgement}

This research is a part of the output under grants GUP-2020-058 Universiti Kebangsaan Malaysia.

\section{References}

Andrew, W., Sejal, B., Mitchell, T., \& Jamie, C. (2018). Prostate cancer: The influence of stigma on qualityof life and relationship satisfaction for survivors and their partners. Journal of Phychosocial Oncology, 37(3), 1-17. https://doi.org/10.1080/07347332.2018.1489442

Brandon, A. K., Linda, M., Lilian, N. C., Martha, O., Cody, C., Bladina, T. M., \& Melissa, H. W. (2019). Serostatus disclosure among cohort of HIV- infected pregnant women enrolled in HIV care in Moshi, Tanzania: A mixed- methods. SSM- Population Health, 7, 1-9. doi.org/10.1016/j.ssmph.2018.11.007

Demiral, O. F., Mayda, P. Y., Yildiz, N., Saglam, H., Kocak, B. K., Habip, Z., Kadak, M. T., Balcioglu, I., \& Kocazeybek, B. (2018). Self- stigma,depression and anxiety levels of people living with HIV in Turkey. The European Journal of Psychiatry, 32(4), 182-186. https://doi.org/10.1016/j.ejpsy.2018.03.002

Eaton, L. A., Driffin, D. D., Kegler, C., Smith, H., Conway-Washington, C., White, D., \& Cherry, C. (2015).The role of stigma and medical mistrust in the routine health care engagement of black men who have sex with men. American Journal of Public Health,105(2), 75-82. doi: 10.2105/AJPH.2014.302322.

Friedland, A. B., Sprague, L., Nyblade, L., Baral, S. D., Pulerwitz, J., Gottert, A., Amanyyeiwe, U., Cheng, A., Mallouris, C., Anam, F., Jackson, A., \& Geibel. S. (2018). Measuring intersectiong stigma among key populations living with HIV: implementing the people with HIV stigma Index 2.0. Journal of the International AIDS Society, 21(5), 115-117. https://doi.org/10.1002/jia2.25131

Goldberg, R. E., \& Short, S. E. (2016). What do we know about childrenliving with HIV-infected or AIDS -ill adults in Sub-Sahara Africa? A systematic review of the literature. AIDS Care, 28(52), 130-141. 130-41. doi: 10.1080/09540121.2016.1176684. 
Hewko, J. S., Cummings, G. G., Pietrosanu, M., \& Edwards, N. (2018). The impact of quality assurance initiatives and workplace policies and procedures on HIV/AIDS-related stigma experienced by patients and nurses in regions with high prevalence of HIV/AIDS. AIDS and Behavior, 22(12), 3836-3846. https://doi.org/10.1007/s10461-018-2066-9

Khadijeh, S., \& Sadigheh, S. T. (2016). Using the health belief model regarding HIV/ AIDS prevention among female high school students. Journal of Research \& Health, 6(1), 161166.

Kementerian Kesihatan Malaysia. (2017). HIV/AIDS Epidemic in Malaysia. Google. Retrieved from http://www.mac.org.my/v3/resources/hiv-statistics.

Kuete, M., Huang, Q., Rashid, A., Ma, X. L., Yuan, H. F., Antezana, J. P. E, Yeltay, R., Rao, M., He, Q., Xiong, C., L., \& Zhang, H. P. (2016). Differences in knowledge, attitude and behavoir towards HIV/AIDS and sexuallty transmitted infection between sexually action foreign and Chinese medical students. BioMed Research International, 26, 1-10. http://dx.doi.org/10.1155/2016/4524862

Li, X., Yuan, L., Li, X., Shi, J., Jiang, L., Zhang, C., Yang, X., Zhang, Y., Zhao, D., \& Zhao, Y. (2017). Factors associated with stigma attitude towards people living with HIV among general individuals in Heilongjiang, Northeast China. BMC Infectious Diseases, 17(1), 1-6. doi: 10.1186/s12879-017-2216-0.

Malaysia AIDS Council. (2016). Malaysia statistics: overview of HIV/AIDS in Malaysia. Google. Retrived from http://www.mac.org.my.

Mao, Y., Li, X., Shan, Q., Zhao, Q., Zhapu, Y., \& Shen, Z. (2017). Social support, stigma and HIV disclosure among parents living with HIV in Guangxi, China. AIDS Care, 30(2), 168-172. doi: 10.1080/09540121.2017.1387639.

Masoudnia, E. (2015). Public perceptions about HIV/AIDS and discriminatory attitudes toward people living with acquired immunodeficiency syndrome in Iran. SAHARA-J: Journal of Social Aspects of HIV/AIDS, 12(1), 116-122. doi: 10.1080/17290376.2015.1123644.

McHenry, M. S., Nyandiko, W. M., Scanlon, M. L., Fischer, L. J., McAteer, C. I., Aluoch, J., Naanyu, V., \& Vreeman, R.C. (2017). HIV Stigma.: Perspectives from Kenyan child caregivers and adolescents living with HIV. Journal International Providers AIDS Care, 16(3), 1-11. doi: $10.1177 / 2325957416668995$.

Nicole, D. W., Joshua, A., \& Clifford, O. (2019). How Much Do They Know? An analysis of the accuracy of HIV knowledge among youth affected by HIV in South Africa. Journal of the International Association of Providers of AIDS Care, 18, 1-7. doi: $10.1177 / 2325958218822306$.

Norfazilah A., Rohaizat, M. H., Incham, A. M., Rizam, M. A. R., Hazlina, M. M., Sazman, W., Azmawati, M. N., \& Qistina, M. G. (2018). Tahap Pengetahuan, Sikap Dan Amalan Terhadap Pencegahan HIV/AIDS Di Kalangan Ibu Muda. International Journal of Public Health Research, 8 (1),913-923. ISSN 2232-0245.

Nyblade, L., Jain, A., \& Grossman, C. (2013). Measuring HIV Stigma and Discrimination Among Health Facility Staff: Standardized Brief Questionnaire. Health Policy Project.

Ofori-Atta, A., Reynolds, N. R., Antwi, S., Renner, L., Nicholas, J. S., Lartey, M., Amissah, K., Tettey, J. K., Alhassan, A., Ofori, I. P., Catlin, A. C., Gan, G., Kyriakides, T. C., Paintsil, E., \& Team, S. S (2018). Prevalance and correlates of depression among caregivers of children living with HIV in Ghana: findings from the Sankofa pediatric disclosure study. AIDS Care, 25, 1-10. doi: 10.1080/09540121.2018.1537463

Okeoma, M., Betty, N., Eliud, A., Anna, L., Brooke, B., Lynae, D., \& Joelle. B. (2016). Perspectives of healthcare providers and HIV-affected individuals and couples during 
the development of a Safer Conception Counseling Toolkit in Kenya: stigma, fears, and recommendations for the delivery of services. AIDS Care, 28(6), 750-757. doi: 10.1080/09540121.2016.1153592

Okumu, E., Jolly, D. H., Alston, L., Eley, N. T., Laws, M., \& MacQueen, K. M. (2017). Relationship between Human Immunodeficiency Virus (HIV) Knowledge, HIV-Related Stigma, and HIV Testing among Young Black Adults in a Southeastern City. Frontiers In Public Health, 5(47), 1-7. doi: 10.3389/fpubh.2017.00047

Ranjan, A., Babu, G., R., \& Detels, R. (2015). Knowledge Attitude and perception about HIV/AIDS among the wives of migrant workers of Muzaffarpur District in Bihar. Journal Community Medical Health Education, 5 (4), 1-8. http://doi.org/10.4172/21610711.1000361.

Richelle, J. J., \& Victoria, A. F. (2017). Moral Development, HIV/AIDS Knowledge and Attitude toward HIV/AIDS among Counselling Students in the United States. International Journal for the Advancement of Counselling, 39, 295-310. https://doi.org/10.1007/s10447-017-9299-6

Sarasuphadi, M., Kamal, S. F., Shah, R. I. A., \& Sabri, A. S. (2018). Faktor-faktor sosial yang mempengaruhi Jangkitan HIV dalam kalangan lelaki berketurunan India HIV positif di Malaysia. Akademika, 88(1).49-64.

United Nations AIDS. (2016). AIDS epidemic update.

West, N., Schwarz, S., Phofa, R., Yende, N., Bassett, J., Sanne, I., \& Annelies, V. R. (2016). “I don't know if this is right....but this is what I'm offering": healthcare provider knowledge, practice, and attitudes towards safer conception for HIV-affected couples in the context of Southern African guidelines. AIDS Care, 28(3), 390-396. doi: 10.1080/09540121.2015.1093596

Kuete, M., Huang, Q., Abid Rashid, A., Ma, X. L, Yuan, H. F., Antezana, J. P. E., \& Zhang, H. P. (2016). Differences in Knowledge, Attitude, and Behavior towards HIV/AIDS and sexually transmitted infections between sexually active foreign and Chinese medical students. https://doi.org/10.1155/20 